\title{
Геокультурные образы буддийского мира тувинцев: исторический контекст и современность"
}

\author{
Чимиза К. Ламажаа \\ Московский гуманитарный университет; Калмыцкий государственный университет, \\ Российская Федерация
}

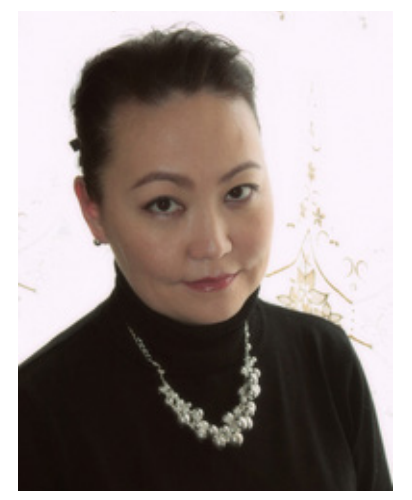

В статье представлен анализ геокультурных образов буддийского мира у тувинцев, которые рассматриваются как представления, сформированные в тувинской культуре для описания территорий распространения буддизма.

Укрепление буддизма на территории Тувы пришлось на вторую половину XVIII - начало ХХ в. При этом колония Китайской империи оставалась замкнутой от внешнего мира. Укоренение буддизма в тувинской культуре позволило появиться тувинскому варианту буддизма. Он усложнил и обогатил мифологическую картину мира тувинцев, связывая их с буддийским миром, но пока на общем уровне космологических представлений. Постсоветское время позволило тувинцам расширить пространственную картину мира. Тува в 1992 г. принимала легендарного буддийского иерарха Далай-ламу XIV, других тибетских учителей, жители республики стали выезжать за границу на буддийские учения. Это позволило буддистам Тувы осознать свою причастность к миру буддийской конфессии и сформировать геокультурные буддийские образы.

Важнейшим из них стал Тибет, колыбель северного буддизма. Однако, в связи с тем, что после 1959 г. изентр тибетского буддизма переместился в индийский город Дхарамсалу, образ получился смещенным - тибетско-индийским («Тибет в изгнании»). Главным фактором этого смещения стала жизнь и деятельность Далай-ламы XIV, который стал выступать персональным цеетром геокультурного образа наиболее известного направления буддизма. Соответственно, буддийский мир воспринимается в связи с деятельностью его лидера, проповедника в изгнании, кочевого центра духовной жизни буддистов.

Рассматриваются также геокультурные образы буддийского мира в России, которые имеют для тувинцев особую значимость.

Ключевые слова: Тува; тувинцы; тувинская культура; пространство; картина мира; религиозный фактор; архаизация; буддизм; буддийский мир; геокультура; геокультурный образ; Тибет; Далай-лама; Шамбала; буддизм России; буддийский регион

" Подготовлено при поддержке Российского научного фонда (проект «Россия и буддийский мир в дискурсе философского востоковедения», грант № 19-18-00118).

\section{Для цитирования:}

Ламажаа Ч. К. Геокультурные образы буддийского мира тувинцев: исторический контекст и современность [Электронный ресурс] // Новые исследования Тувы. 2019, № 3. URL: https://nit.tuva.asia/nit/article/view/862 (дата обращения: дд.мм.гг.). DOI: 10.25178/nit.2019.3.3

Ламажаа Чимиза Кудер-ооловна - доктор философских наук, заместитель директора по научной работе Института фундаментальных и прикладных исследований Московского гуманитарного университета, приглашенный исследователь Калмыцкого государственного университета. Адрес: 111395, Россия, г. Москва, ул. Юности, д. 5, корп. 6, каб. 18. Тел.: +7 (499) 374-73-90. Эл. адрес: lamazhaа@tuva.asia ORCID ID: 0000-0003-1813-3605

Lamazhaa Chimiza Kuder-oolovna, Doctor of Philosophy, Deputy Director, Institute of Fundamental and Applied Studies, Moscow University for the Humanities; Visiting Researcher, Kalmyk State University. Postal address: 5 Yunosti St., 111395 Moscow, Russian Federation. Tel.: +7 (499) 374-73-90. E-mail:lamazhaa@tuva.asia 


\title{
Geocultural images of the Tuvan Buddhist world: historical context and modernity"
}

\author{
Chimiza K. Lamazhaa \\ Moscow University for Humanities, Russian Federation
}

\begin{abstract}
The article analyzes geocultural images of Buddhist world of the Tuvans. These images are viewed as concepts, which were formed in the Tuvan culture to describe the areas where Buddhism has spread.

The strengthening of Buddhism in Tuva occurred between the second half of the 18th and the early20th centuries. At the same time, the colony of the Chinese Empire remained closed to the outside world. The rooting of Buddhism in the Tuvan culture created its specific Tuvan version. It made the mythological world view of Tuvans richer and more complex, linking them to the Buddhist world largely on the level of general cosmological ideas. Post-Soviet period let Tuvans enlarge their spatial world view. In 1992 the legendary Buddhist hierarch Dalai Lama XIV visited Tuva, as did other Tibetan teachers, and Tuvans began to travel abroad for Buddhist teachings. That let Buddhist Tuvans realize their belonging to the Buddhist world and form geocultural Buddhist images.

Tibet became the most important of those because it is the cradle of the northern Buddhism. However, it appeared in a shifted Tibetan-Indian version ('a Tibet in exile') since the centre of Tibetan Buddhism has moved to the Indian city of Dharamsala. The main reason for that was Dalai Lama XIV' life and activity. He became a personal centre of a geocultural image, representing the most famous branch of Buddhism. Thus, the Buddhist world is perceived as a nomadic center of Buddhists'spiritual life, due to the activity of its leader, a preacher in exile.

The article also considers geocultural images of Buddhist world in Russia, which are of great importance for Tuvans.
\end{abstract}

Keywords: Tuva; Tuvans; Tuvan culture; area; world view; religious factor; archaization; Buddhism; Buddhist world; geoculture; geocultural image; Tibet; Dalai Lama; Shamballa; Russian Buddhism; Buddhist region.

"The article was prepared with support from the Russian Science Foundation, Grant No. 19-18-00118, «Russia and the Buddhist world in the discourse of the philosophy of Oriental Studies».

For citation:

Lamazhaa Ch. K. Geocultural images of the Tuvan Buddhist world: historical context and modernity. The New Research of Tuva, 2019, no. 3 [online] Available at: https://nit.tuva.asia/nit/article/view/862 (access date: ...). DOI: 10.25178/ nit.2019.3.3

\section{Введение}

Республика Тыва (Тува) входит в число трех буддийских регионов России, вместе с Калмыкией и Бурятией, большая часть населения которых традиционно исповедует буддизм. Соответственно Тува, оставаясь субъектом Российской Федерации, является частью буддийского мира и тем самым имеет религиозный центр за пределами страны, главной фигурой которого является Его Святейшество Далайлама XIV. Поскольку буддизм известен толерантностью, миролюбием, этичностью и экологичностью, это религиозное тяготение Тувы не имеет значительных геополитических проблем, оно лишь показывает пример сложного многополярного глобального мира, частью которого в свою очередь является сама Россия. Сегодняшний мир взаимосвязан, он имеет много центров в самых разных областях планеты производственных, торговых, финансовых, образовательных, религиозных и др. Это и мир суверенных государств, и в то же время трансграничный мир. Тува - это, с одной стороны, азиатский регион российского государства, важный элемент единства европейского и азиатского начал российской культуры. С другой стороны, это часть буддийского мира. Поэтому исследование этих взаимосвязей помогает постижению российской многокультурной идентичности, которая при всей своей целостности и евразийском своеобразии имеет несколько полюсов в контексте глобального мира.

Другой аспект актуальности проблемы усложнения российской идентичности связан с тем, что сегодня Тува, как и практически все регионы страны и миры (за исключением совершенно закрытых и 
труднодоступных регионов), испытывает на себе глобализационные процессы и влияние вестернизации. Жители и городов, и сел республики стали частью глобального рынка, потребления и связи: они пользуются мобильными телефонами, Интернетом; водят машины и российского, и иностранного производства; одеваются в одежды иностранных марок; дети, как и почти все дети мира, играют с игрушками образами западной поп-культуры, с удовольствием следя за новинками голливудской киноиндустрии. Представление тувинцев о мире претерпело существенные изменения. Распространение образования и научной картины мира, увеличение межкультурных контактов, расширение понимания пространства все это усложнило идентификационную «карту» современных тувинцев.

Тем не менее, этнокультурная идентичность накладывает свой отпечаток на восприятие человеком пространства: пространства своей культуры, пространства других культур. При этом восприятие это возникает в виде мыслительного образа пространства или геокультурных образов, которые Д. Н. Замятин определяет как геопространственные знаки, символы, представления, сформированные в культуре для описания каких-либо реальных пространств (территорий, местностей, регионов, стран и пр.). Правда Замятин говорит, прежде всего, о геокультурных образах как об экзогенных географических образах, в формировании которых играют большую роль другие культурные миры (Замятин, 2006: 63). Но «нет культуры вне пространства, а пространство есть всегда культурно осмысливаемая субстанция», подчеркивают антропологи (Малькова, Тишков, 2009: 4). Более того, наличие пространственных образов культур - формируемых, развивающихся, транслируемых - может рассматриваться как проявление локализации в противовес глобализации. Геокультурные образы выражают определенное мировидение культуры, в свою очередь они оказывают влияние на формирование и развитие самой культуры, определяя ее ориентиры, уточняя вопросы самоидентификации представителей культуры (Гачев, 1999). А когда речь заходит о кочевых культурах, к числу которых относится традиционная тувинская культура, вопрос становится еще более интересным, поскольку, как пишут А. В. Головнев, Д.А. Куканов и Е. В. Перевалова, кочевники имеют особую философию движения, искусство движения, что позволило им создать стратегию контроля или даже власти над пространством (Головнев, Куканов, Перевалова, 2018). И подобная философия, по мнению исследователей, это не увядающая традиция, а школа движения для современных людей, «которая дает нам уроки мобильности и адаптивности» (там же: 4).

Поэтому обращение к теме локальных пространственных представлений, географических образов в контексте современных общих трансформаций категории пространства вызывает также особый исследовательский интерес и может иметь много аспектов. В настоящей работе мы сконцентрируемся на анализе геокультурных образов буддийского мира у тувинцев, который будет иметь ретроспективный характер для понимания особенностей их складывания.

Эта тема поднимается практически впервые в научной литературе ${ }^{1}$, несмотря на значительное число работ по буддийским основаниям тувинской культуры, по вопросам идентичности тувинцев и их представлениям о других народах, которые затрагивают близкие, смежные вопросы. Решение обозначенной проблемы будет производиться с использованием сведений истории, этнографии, культурологии, географии, лингвистики, религиоведения и др. научных областей, которые будут анализироваться и обобщаться методами философского анализа. В числе наших задач здесь: во-первых, обобщение сведений об укоренении буддизма в Туве, во-вторых, определение степени влияния буддийского фактора на картину мира тувинцев; в-третьих, анализ состояния буддийской идентичности тувинцев сегодня; в-четвертых, обобщение сведений о развитии буддизма в Туве в XX веке; в-пятых, выделение и анализ геокультурных буддийских образов тувинцев сегодня. При этом, безусловно, в одной статье весь комплекс вопросов не решить, поэтому мы попытаемся лишь сформулировать наиболее важные тезисы для последующего развития исследования.

Источниковой базой для нас выступают в первую очередь имеющиеся публикации специалистов по истории и культуры Тувы, а также исследования по состоянию буддизма в России. Также важной основой для заключений автора стали собственные многолетние наблюдения за религиозной жизнью тувинцев в Туве.

\footnotetext{
${ }^{1}$ Из совсем свежих публикаций, наиболее близких по проблематике геокультурных образов тувинцев, можно назвать интересное исследование по одному геокультурному образу в представлениях тувинцев - по образу своей страны - России, см.: Шестопал, Смулькина, Сорозикова, 2019. Общие вопросы самоидентификации тувинцев с восточной культурой, с регионами Азии рассматривала М. В. Монгуш (Монгуш, 2010: 165-182). По геокультурным образам буддизма у калмыков, например, есть исследования (см.: Китинов, 2018).
} 


\section{Буддизм Тувы: волны и укоренение}

Тувинцы - изначально шаманисты, они далеко не всегда были буддистами. Буддизм сложно проникал в среду кочевников, тем не менее он стал важной частью их культуры, более того - фактором развития культуры, ее эволюционного усложнения и расширения пространственного аспекта картины мира. Как это происходило?

Буддизм, возникший в VI в. до н. э. в Индии и распространившийся за более чем два тысячелетия по всему миру, имел сложную историю укоренения в различных регионах, в том числе и в Туве. Этому предшествовало несколько этапов, которые А. Берзин назвал волнами (Берзин, 1992). Первая известная волна относится к времени существования первого Тюркского каганата, которая была не очень продолжительной, незначительной и практически не оставила следов (Берзин, 1992: 15; Монгуш, 2001: 13). Второй этап (или вторая волна), относится к расцвету Монгольской империи в ХІІІ в. и политикой пятого Великого хана Хубилая, активно поддержавшего буддийскую сангху (там же: 16-26). Эта волна оказалась более успешной, но буддизм был религией преимущественно правящих кругов, оставаясь чуждой для широких народных масс. Третья, самая крупная волна распространения буддизма в Центральной Азии, которая ознаменовалась массовым принятием его в качестве официальной религии монгольских кочевников, относится к периоду существования государства Алтын-ханов (XVI-XVII вв.). Здесь распространился тибетский буддизм традиции Гелуг (Берзин, 1992: 23). Территория Тувы также входила в состав этого государства и, как пишет А. Берзин, тибетский буддизм сюда пришел через Монголию в XVIII в. (там же: 24). Тувинские племена были вовлечены в общий процесс распространения традиций монастырской жизни, буддийских идей, обрядности и ритуалов. Тем не менее, как подчеркивает М. В. Монгуш, Тува, в отличие от Монголии, была лишь принимающей буддизм территорией, нежели активно воспроизводившей и преумножающей традиции (там же: 35).

Таким образом, начиная с XVI в. буддизм укоренился в жизни коренных народов Центральной Азии, привнеся много нового в их повседневный быт, материальную и духовную культуру. В Туве буддизм исповедовали все слои общества - знать и рядовые тувинцы, особенно кочевавшие при ставках правителей, где находились и буддийские монастыри - хурээ (История Тувы, 2001: 212). Буддизм считался официальной религией, тем не менее основная масса тувинцев оставалась шаманистами, сохранившими древние культы, в том числе, например, погребальные. Но в районах влияния буддийских монастырей были распространены буддийские обряды. В целом, религия, как подчеркивает религиовед М. В. Монгуш, значительно обогатила культуру местных народов, в том числе и их систему народных верований. При этом и сам буддизм трансформировался под их влиянием (Монгуш, 2001: 35).

Окончательно национальное своеобразие буддизм в Туве, также, как и в Калмыкии и Бурятии, пишет М. В. Монгуш, приобрел в XIX в. (Монгуш, 2001: 4). С конца XVIII - во второй половине XIX в. выросло число буддийских храмов, появились первые монастырские комплексы, увеличились их размер и число служителей в них. Затем произошли уже качественные изменения, определившие не только социальную структуру каждого монастыря, но и положение сангхи как самостоятельной социально-политической силы, с которой считалась светская власть (там же: 54). Характер отношений между религией и властью в Туве позволил М. В. Монгуш рассматривать буддизм как государственную религию в Туве (там же: 55).

Итак, буддизм имел сложную многовековую историю проникновения в Туве, обосновавшись здесь, как и в других российских регионах, не сразу, будучи сначала насаждаемым властью в качестве официальной религии. На первых порах социальной задачей религии было установление власти монгольских ханов, в том числе путем распространения единой письменности, авторитетов, ритуалов, мифологии. Лишь впоследствии буддизм был постепенно принят населением, причем не в полной мере. Синкретизация религий, достаточно подробно исследованный на материалах традиционных религий народов Саяно-Алтая О. М. Хомушку, это достаточно сложный и длительный процесс, успешность которого обусловлена тем, что на место прежних божеств становятся святые новой религии с аналогичными функциями (Хомушку, 2010: 263). Буддизм прошел в Туве также подобный путь, что и позволило ему стать «своей» религией, укорениться в тувинской культуре.

\section{Обогащение пространства тувинской культуры}

Шаманизм и древние культы долго сохраняли (и до сих пор сохраняют!) для рядовых тувинцев свое значение, особенно в ряде районов. Тем не менее такая особенность буддизма как приспособляемость к культурам различных стран, где он распространяется (Берзин, 1992: 11), позволила ему укрепиться в 
Туве и приобрести «тувинскую» форму. В ней также, как и в других территориях, присутствовали два уровня: рафинированный философский и мистический буддизм высшего духовенства - ламства и народный буддизм (Хомушку, 1998: 38). Очевидно, что знание реального пространства, представления об отдаленных странах у образованных лам, знающих и буддийское учение, и иерархию буддийского мира, а также представления простых аратов об отдаленных территориях - были различными. То есть можно говорить о двух системах понимания пространства. Процент образованных был значительно меньше и, к сожалению, особенности их культуры изучены меньше ${ }^{1}$. Нас же в данном случае интересует более изученное мифологически-религиозное понимание мира, распространенное у населения.

Укрепление буддизма на территории Тувы пришлось на период, когда край был присоединен к Цинской империи Китая (вторая половина XVIII - начало XX в.). Условия, в которых оказалось население, также сохраняли консервацию пространственного миропонимания тувинской культуры. Китайская администрация во внутренние дела тувинского населения не вмешивалась, управление осуществлялась через Монголию и с помощью наместников из числа местной знати, от тувинцев в целом империи лишь требовались в первую очередь налоги (История Тувы, 2001: 216-217). Поэтому край оставался замкнутым от внешнего мира, тувинские племена существовали разрозненно, в том числе будучи разделенными китайским административным устройством и приписыванием к определенным хошунам. Культура оставалась «замкнутой» на понимании прежде всего своего локального мира.

Тем не менее общие пространственные ориентиры в культуре были. Как пишут исследователи, начиная с текстов памятников рунической письменности нам известно, что у тюрков были абсолютно определенныепредставления осторонахсвета,которыебылисформированыв соответствиисположением человека и Солнца (Традиционное мировоззрение ..., 1988: 42-46). В. Ю. Сузукей уточняет, что у тувинцев понимание сторон света исходило из особенностей движения Солнца не столько относительно Земли, но и «галактического» движения Солнца и других планет системы, что нашло свое отражение в терминологии тувинского языка (Сузукей, 2009: Электр. ресурс). В целом, еще Л. П. Потапов писал о том, что знания тувинцами движения и особенностей звезд, созвездий, перемежаясь с мифологическими, иррациональными трактовками, представляют собой богатое исследовательское поле (Потапов, 1969: 292), которое, на наш взгляд, еще ждет своих исследователей.

Пространство и время тувинцев были максимально конкретны и предметны, характеристики макрокосмоса переносились на микрокосмос, выражаясь в особом понимании структуры жилища, его сторон и должного поведения. Иные территории, кроме своих знакомых мест, были чужими местами. Чужими и чуждыми. Это отражалось в фольклоре: герой сказаний, уезжавший далеко, попадал в иной мир, порой впадал в беспамятство. Одним из важных признаков принадлежности к реальному миру считалась видимость. Если «нечто» не видят, но слышат, это «нечто» принадлежит иному миру, и эта область, куда попадал герой эпоса, имел характеристики иного мира. В таком понимании мира самыми большими «мастерами» в освоении мифологического пространства-времени были шаманы (Традиционное мировоззрение ..., 1988: 76-81).

В такой культуре, локальной, замкнутой, буддизм, вписавшись в картину мира, трансформировал ее мифологию и в том числе понимание пространства. О. М. Хомушку пишет о трансформации образа верховного божества Тэнгри, который стал носить несколько расплывчатый характер. Появился образ Бурхана-башкы. Деление мира на три части сохранилось, но миры дополняются новыми персонажами, а, например, один из традиционных небожителей Ээрлик переместился в нижний мир (Хомушку, 2010: 260-261). Культы неба и земли были переосмыслены и дополнены новыми идеями в соответствии с принципами буддийской космологии и учением о трех мирах или сферах: чувственным миром, миром форм и миром не-форм, которые населялись разными существами. Представления о трех сферах соотносились с различными стадиями измененных состояний сознания и содержательными аспектами буддийской йоги, но содержали теорию традиционной космографии и основной частью сангхи воспринимались в качестве реального знания, т. е. землеописания (Буддийский взгляд на мир, 1994: 101-102). При этом будучи аналогом свода географических знаний, буддийская космография тем не менее не была отражением географических реалий (там же: 103).

\footnotetext{
${ }^{1}$ Здесь мы можем лишь отметить, что Тува, Калмыкия и Бурятия долгое время не имели прямой связи и подчинения тибетскому центру в связи с политикой российской империи (в состав которой Калмыкия и Бурятия вошли гораздо раньше Тувы), и китайской империи, колонией которой была Тувы - тогда Урянхайский край. Соответственно буддизм в регионах развивался относительно автономно как от Тибета, так и друг от друга, что должно было отразиться на слабой развитости геокультурных образов буддизма даже в среде просвещенных лам.
} 
Интересна схема формирования тенгрианско-шамано-буддийского синкретизма, которую составила О. М. Хомушку. Она показала, какие божества тенгрианско-шаманского пантеона заменились на божества-аналоги, сформированные под буддийским влиянием (Хомушку, 2010: 263). В итоге, небесный мир позднейших тюрков Южной Сибири стал выглядеть как «слоеный пирог»: небо было разделено на горизонтальные ярусы, которые были густонаселены не только звездами, светилами, но и духами (там же: 92). Подземный мир был «разработан» еще более подробно. Там обитают умершие люди и всевозможные существа (там же: 95-97).

Важная причина успешного синтеза двух религиозных систем - местного шаманизма и буддизма заключалась также в том, что, как подчеркивает О. М. Хомушку, тибетский вариант буддизма сам в свое время испытал влияние национальной религии тибетцев - бон, космология которой была построена на триаде «небо, земля и подземный мир» (Хомушку, 2009: 72). Еще одной причиной автор называет общность представлений о роли и месте человека в мире как в шаманском, так и в буддийском миропонимании. Если для первой системы человек связан с природой, с предками и родом, то для первой эта связь имеет более широкий фон - колесо сансары, где смерть не есть конец, но лишь переход к иной форме существования сознания - к промежуточному существованию, которое неизбежно предшествует новому рождению (Буддийский взгляд на мир, 1994: 121).

Так, укоренение буддизма в тувинской культуре позволило появиться тувинскому варианту буддизма, который усложнил и обогатил мифологическую картину мира тувинцев, связывая их с буддийским миром сначала на общем уровне космологических представлений.

\section{Буддизм Тувы в ХХ веке}

Жизнь религий в XX веке, как мы знаем, была тяжелой и наполненной трагическими событиями. В начале века буддизм, оставаясь официальной религией Тувы, сыграла существенную роль в создании и укреплении государственности - Тувинской Народной Республики, провозглашенной в 1921 г. Однако, с 1929 г., после Пленума ЦК ТНРП, когда партийная власть лишила сангху поддержки и собственности, фактически стала внедряться политика замены религии на коммунистическую идеологию. Буддизм и его служители подверглись гонениям, даже большим, чем шаманы, поскольку монастыри рассматривались как трибуны для провозглашения реакционных идей ламами (Монгуш, 2001: 105-106). Хурээ были уничтожены, ламы ограничивались в деятельности все больше, а впоследствии стали ссылаться и физически уничтожаться. Процесс секуляризации затем сменился процессом атеизации, который стал частью внутренней политики республики, в 1944 г. вошедшей в состав СССР.

М. В. Монгуш констатировала, что в советское время буддийская культура в том виде, в котором она существовала в XX в., полностью перестала существовать (Монгуш, 2010: 133). Тем не менее она писала о неофициальной деятельности хурээ и молитвенных домов в Дзун-Хемском районе (Монгуш, 2001: 121-124), a О. М. Хомушку - о контактах тувинских лам с бурятской сангхой (Хомушку, 1998: 103-106). Закрытие в 1960 г. последнего буддийского центра в Туве, отметила М.В. Монгуш, автоматически привело к утрате буддийского учения (Монгуш, 2010: 135), однако она же подчеркнула, что речь идет об институциональной практике, которая стала вытесняться внеинституциональной, о чем говорит нелегальная деятельность лам и шаманов в Дзун-Хемчикском, Барун-Хемчикском, Бай-Тайгинском, Овюрском и Тоджинском районах (Монгуш, 2001: 123; Монгуш, 2010: 135). О. М. Хомушку писала, что полной изоляции представителей церкви от людей не удалось добиться, поскольку властью учитывались только внешние показатели: наличие действующих монастырей, богослужений, количество лам и шаманов (Хомушку, 1998: 92-93).

Кроме того, официально буддизм в СССР не был уничтожен. В 1946 г. было принято «Положение о буддийском духовенстве СССР», которое обязывало лам почитать наравне со своей верой Родину трудящихся; было образовано Центральное Духовное Управление буддистов СССР. Резиденцией ЦДУБ стал новый храм в Бурятии, ныне - Иволгинский (Терентьев, 2014: 144-145). Вскоре был открыт Агинский дацан в Читинской области (там же: 146). Их деятельность строго ограничивалась и использовалась советской властью в том числе для решения внешнеполитических задач при реализации международных буддийских связей (там же: 154; Горбатов, 2018). Соответственно, контакты между легальными и нелегальными общинами, деятельность степных (бродячих) лам (там же: 86), а также наличие поколения, которое помнило о действующих храмах и авторитете духовных учителей, и поколения, которое уничтожало храмы и тогда искренне верило в правильность своих деяний (Монгуш, 2001: 114) - все это обусловило наличие у тувинцев живой исторической памяти о буддизме. Об этом упоминала Н. П. Мос- 
каленко (Москаленко, 2000: 23; Монгуш, 2001: 128). О. М. Хомушку писала, что «несмотря на столь разветвленную пропагандистскую систему, влияние традиционных религиозных верований все же было достаточно устойчивым», и этот факт «поражает» (Хомушку, 1998: 105).

Итак, в XX веке буддийская культура тувинцев не исчезла полностью, она была лишь вытеснена на несколько десятков лет на периферию общественной жизни и при определенных условиях в конце века была возвращена, позволив верующим осознать геокультурную приобщенность к буддийскому миру.

\section{Буддизм Тувы на рубеже $X X-X X I$ веков}

Такие условия появились с конца 1980-х гг. после объявления перестройки, а особенно в 1990-е годы, когда в стране развернулись кризисные явления во всех сферах общественной жизни, когда доверие населения к власти упало до минимума, когда экономика практически рухнула, и важнейшей стратегией стала стратегия выживания. Это вылилось в развитие процессов архаизации - обращения к архаическим социокультурным практикам связей, отношений (Ламажаа, 2013). В условиях ценностного вакуума и аномии также начался поиск духовных ориентиров и возрождение традиционных религий, в том числе буддизма - как и в Калмыкии, в Бурятии (помимо этого, возрождение буддизма в России получило еще одну - нетрадиционную форму: появились буддийские общины, кроме традиции Гелуг, и Тхеравады, Чань/Дзэрн-буддизма, Карма-Кагью, Ньингма и др. в крупных городах страны (Религиоведение, 2007: 81)).

Процесс был подкреплен и государственными мерами: принятием в 1990 г. и союзного закона «О свободе совести и религиозных организациях», и закона РСФСР «О свободе вероисповеданий», что нашло отражение в Конституции РФ 1993 г. В Туве также были приняты соответствующие акты, согласно которым традиционными верованиями населения были признаны шаманизм, буддизм и православие. Получили регистрации первые религиозные организации. Были построены новые храмы, в них стали работать священнослужители, появился центр буддийского духовенства - Управление Камбы-ламы Тувы. Стали практиковать и шаманы, работая как по одиночке, так и образуя некие профессиональные союзы (Харитонова, 2018: Электр. ресурс).

Здесь также необходимо вспомнить о том, что в советское время Тува была практически недоступна иностранцам. Помимо общего «железного занавеса», отделявшего Советский Союз от стран Запада, как пишет Т. Левин, «существовало и множество мелких “железных занавесок”, разделявших пространство внутри СССР и призванных предотвращать попадание иностранцев из капиталистических стран <...> Приграничные регионы вроде Тувы считались “номинально закрытыми”. Это означало, что несмотря на отсутствие в этих районах секретных военных объектов, для поездки туда гражданину из “капстраны” требовалось специальное разрешение» (Левин, 2012: 39).

Открытие «железного занавеса» позволило совершать личные визиты верующих, развивая и укрепляя связи, атакже расширяя знание оботдаленныхтерриториях. Особозначимой вехой стал визит в республику в 1992 г. Далай-ламы XIV, в ходе которого он преподал буддийское учение десяткам тысячам жителей Тувы. В числе мероприятий было его выступление на главной площади столицы республики, которое также смогла услышать и автор статьи, но не в качестве исследователя, а в качестве заинтересованного слушателя. Первый президент Тувы Ш. Д. Ооржак тогда попросил буддийского лидера освятить флаг республики и весь народ, чтобы слушатели могли «очистить, поправить души» («... Страданий рассеивать тьму..», 1995: 19-20). Его Святейшество Далай-лама XIV в ответном слове благодарности подчеркнул миролюбие религии, ее конструктивное начало (там же: 37-38). Этот визит хотя и был кратковременным, а также остался в истории республики единственным ${ }^{1}$, тем не менее стал мощным толчком в деле возрождения буддизма (Монгуш, 2010: 142). Он установил и связи между буддистами Тувы и Тибета, а также вдохновил верующих республики на дальнейшие шаги по возрождению религиозности.

Современное состояние религиозности в Туве характеризуется устойчивой положительной динамикой: увеличением числа религиозных буддийских организаций, строительством храмов на месте разрушенных, увеличением количества буддийских ступ - субурганов, постепенно растущим числом тувинцев, причисляющих себя к буддистам. В публикации 1998 г. О. М. Хомушку отмечала наличие в Туве 13 зарегистрированных буддийских организаций в составе 26 религиозных (Хомушку, 1998: 108). В 2000 г., по сведениям М. В. Монгуш, на территории Тувы действовало уже зарегистрированных 20 буд-

${ }^{1}$ До этого Далай-лама XIV бывал в Советском союзе в 1979, 1982, 1986 и 1991 гг., но в других республиках (Терентьев, 2014: 184-186). Другие буддийские иерархи также посещали страну, однако встречались они с буддистами других регионов (там же: 180). 
дийских организаций, из общего числа 44 религиозных организаций (Монгуш, 2001: 137). На июнь 2019 г., по данным Министерства юстиции РФ, буддийских организаций насчитывается 22 из общего числа религиозных организаций $-58^{1}$.

Данные социологических опросов разных авторов по религиозной принадлежности тувинцев показывают различные цифры. По сведениям О. М. Хомушку, в 1996 г. буддистами себя называли 52\% тувинцев, при том, что шаманистами - 19\% (Хомушку, 1998: 108). В 1999 г. автор насчитала 49,27\% буддистов (Хомушку, Электр. ресурс). В 2001 г. в исследовании В. С. Донгак была получена цифра 82,5\% буддистов среди тувинцев (Донгак, 2003: 24), а у 3. Ю. Анайбан в 2004 г. насчитывалось 80\% (Анайбан, Тюхтенева, 2008: 71). Расхождения в цифрах 3. В. Анайбан объясняет разными методиками опросов. Она подчеркивает, что в любом случае очевиден рост религиозной активности населения, и прежде всего - буддизма (там же: 70-71). Значимость религиозной принадлежности растет и среди молодежи. Так, например, в 2015 г. 3. В. Анайбан в социологическом опросе молодежи Тувы зафиксировала, что 83\% молодежи тувинской национальности называют себя буддистами (Анайбан, 2017: 169).

Следует также отметить, что провозглашенная свобода вероисповедания и активная деятельность на территории республики религиозных организаций самого разного происхождения существенно разнообразили конфессиональную карту региона, в нем появились новые религиозные течения, например, южнокорейской церкви христиан веры евангельской «Сун Бок Ым», общины Свидетелей Иеговы, миссионерского общества «Христианин» и ряда других религиозных движений. Тувинцы также были охвачены этими новыми тенденциями. Религиоведы отмечают достаточно успешное распространение среди коренного населения нетрадиционных религиозных сект (Хомушку, 2005: 3; Монгуш, 2012ab: Электр. ресурс).

Тем не менее, для местного населения, ориентированного на традиционную конфессию, весомым также является фактор поддержки религии властью. Поддержка республиканских властей обеспечена прежде всего буддийским учреждениям и в целом, буддийскому учению (несмотря на отдельные эпизоды противостояния²). Централизация буддийских организаций в форме Управления Камбы-ламы Тувы, первые выборы главы буддизма республики также проходили при активной поддержке правительства Тувы. Отправка учеников в буддийские образовательные центры Индии также происходит при участии местной власти. Соответственно, данные меры и официальные декларации также способствуют развитию буддизма в республике, население которой предпочитает иметь устойчивое понимание связи между властью и религией (несмотря на провозглашаемую свободу совести и вероисповедания и официальное разделение между светской и духовной властями).

Так, постсоветское время с его свободами позволило тувинцам расширить пространственную картину мира и «оживить» свой религиозный центр: увидеть лично легендарного буддийского иерарха, принимать тибетских учителей, а также самим выезжать за границу на буддийские учения. Важнейшим итогом такого «оживления» стало осознание своей причастности к миру буддийской конфессии и формирование геокультурных буддийских образов.

\section{Геокультурные образы буддйского мира современных тувинщев}

Что же конкретно изменилось в пространственном миропонимании у тувинцев-буддистов?

Важнейшим геокультурным образом для буддистов Тувы, разумеется, в первую очередь стал Тибет, колыбель северного буддизма, откуда религия и пришла в республику, духовных наставников которых признают буддисты Тувы, Бурятии, Калмыкии. Я также могу подтвердить слова М. В. Монгуш, которая пишет о широкой распространенности у тувинцев плакатов с изображением Поталы в Лхасе, кассетах с медитативной музыкой, украшений с буддийской символикой тибетского производства, гербе и флаге Тибета, которые можно приобрести в специализированных магазинах и киосках Кызыла (Монгуш, 2010: 175).

Однако, пока в советское время религии в российских регионах существовали в подпольной форме, в середине XX века жизнь самого Тибета значительно изменилась - в 1959 г. страна была оккупирована Китаем, глава страны и высший иерарх церкви Далай-лама XIV был вынужден покинуть родину и вместе с тысячами тибетцев отправиться в изгнание в Индию. Здесь он проживает до сих пор и с этой страной

\footnotetext{
${ }^{1}$ По данным информационного портала Министерства юстиции РФ: http://unro.minjust.ru/NKOs.aspx

${ }^{2}$ Речь идет о разногласиях, обсуждавшихся в СМИ республики, между буддистами Тувы и правительством республики - по поводу планов строительства буддийского храма в центре Кызыла в 2011 г. без учета мнения буддийской общины.
} 
связана уже бо́льшая часть его жизни. С тех пор фактически центр тибетского буддизма переместился в индийский город Дхарамсалу в штате Химчал-Прадеш, на южных склонах Гималаев, где и проживает община тибетских беженцев. Его Святейшество за эти годы успел сложить с себя полномочия главы правительства (в 2011 г.), оставшись лишь духовным лидером буддистов. Именно сюда и устремляются с тех пор тысячи паломников, жаждущих увидеть и услышать слова наставления от Далай-ламы. Его проповеди ненасилия, идеи зоны мира во всем мира, политика Срединного пути, с которыми он выступал во многих странах, сделали его чрезвычайно популярным, уважаемым религиозным деятелем современности, принеся ему Нобелевскую премию мира 1989 г. и ряд других государственных наград самых разных стран, включая США. Сам же Тибет остался автономным районом Китайской Народной Республики и, хотя иностранцам его можно посещать, но это позволено только в туристических целях. Регламентирование посещений сложное и контроль властей строгий.

Поэтому Тибет как образ центра тибетского буддизма у тувинцев, очевидно, что также, как и у калмыков, и бурят, фактически получился смещенным - тибетско-индийским. Хотя численность тибетцев в КНР превышает число беженцев, центр его культуры считается смещенным. Для этого феномена есть даже устойчивые термины «Тибет в изгнании», «правительство Тибета в изгнании».

И важнейшим фактором этого смещения стала жизнь и деятельность в изгнании Далай-ламы XIV, который стал выступать персональным центром геокультурного образа мирового буддизма. Мирового, несмотря на то, традиция Гелугпа - направление тибетского буддизма - считается одной из множества буддийских школ.

Соответственно, буддийский мир воспринимается в первую очередь не в связи с определенной локализацией, ав связисдеятельностьюеголидера.Иэтонеудивительно,учитывая особенности буддийского вероучения, направленного прежде всего на задачи самосовершенствования самого человека. Как выразился в одной из поздравительных телеграмм с очередным днем рождения Его Святейшества глава Тувы Ш. Кара-оол: «Ваша безграничная доброта, милосердие и мудрость являются светлой путеводной звездой в нашей жизни»1. Можно сказать без преувеличений, что Его Святейшество Далай-лама XIV своей многолетней подвижнической деятельностью, безупречной репутацией и духовным авторитетом в полной мере оправдывает звание «далай-ламы»- «море-ламы», или ламы с властью, безграничной как море (в переводе с монгольского и тибетского языков). Согласно традиции школы Гелугпа каждый Далайлама считается воплощением бодхисаттвы Авалокитешвары - воплощением бесконечного сострадания всех будд. Оставаясь лидером тибетского народа и буддийской церкви, он своим примером показывает, что центр буддийской веры может не иметь пространственной локации, что буддизм связывается с человеческим сознанием и деятельностью, с учением о нравственности, с постоянным поиском мудрости. Вынужденно став проповедником в изгнании, он стал кочевым центром духовной жизни буддистов.

И, понимая Далай-ламу самого как источник мудрости и величайшего благословения, паломники приезжают к нему послушать его учения, и не только в Дхарамсалу, но и отслеживая на Интернетсайтах (dalailama.com, savetibet.ru и др.) графики его учений и поездок в разные города мира. С 2009 г. он стал проводить в Индии учения ежегодно специально для буддистов России и с каждым годом число паломников все растет. М. В. Монгуш даже использовала для этой тенденции слово «Мекка» (Монгуш, 2010: 175).

Пример Его Святейшества, а такжедругих буддийских иерархов, ведущих активную проповедническую деятельность в разъездах в самых разных странах мира, сила их личностей, медитации - все это способствовало не только укреплению религиозности в традиционно буддийских регионах, но и распространению буддизма на Западе, привело к появлению нетрадиционно западного варианта буддизма (Монгуш, 2016: Электр. ресурс). В итоге, современная буддийская геокультура стала сложнее, мобильнее. Более того, современный буддизм пытается наладить связи с научным знанием. Эту позицию неоднократно высказывал Его Святейшество: буддизм не противоречит науке2.

Образ Тибета и его лидера в изгнании напоминает нам о еще одном «смещенном» образе буддийского пространства - Шамбале. Это место пребывания мудрецов и мистиков в тантрическом буддизме (Андросов, 2017: 681), он присутствовал и в классическом индуизме, упоминание о нем есть в

\footnotetext{
${ }^{1}$ Глава Тувы направил поздравительную телеграмму Его Святейшеству Далай-Ламе XIV (2013) [Электронный ресурс] // Официальный портал Республики Тыва. 6 июля. URL: http://gov.tuva.ru/press_center/news/society/3813/?sphrase_id=43773 (дата обращения: 12.05.2019).

2 Далай-лама принял участие в международной конференции «Буддизм и наука» в Улан-Баторе (2016) [Электронный ресурс] // Его Святейшество Далай-лама XIV. URL: https://ru.dalailama.com/news/2016/international-conference-on-buddhismand-science (дата обращения: 12.03.2019).
} 
«Махабхарате». Шамбала считается мифическим местом для всех рационалистов, однако для верующих, начиная с Его Святейшества Далай-ламы XIV, - это реальная страна. Реальная, но в иной реальности, которую надо только постигать трансцендентным путем, путем специальных практик. Как пояснил духовный лидер буддистов в интервью М. В. Монгуш: «Шамбала совершенно точно есть. ... Но она не существует на таком физическом уровне, как, например, наша планета. Ее местонахождение нельзя определить так: садитесь на такой-то самолет, летите туда-то и там попадете в Шамбалу. Она существует на другом уровне реальности, в более тонком мире. Вход в нее крайне ограничен, а потому для большинства недоступен. Во всяком случае за одну жизнь попасть туда нереально, если нет достаточных кармических накоплений, т. е. благих заслуг» (Монгуш, 2014: Электр. ресурс).

Образ Шамбалы вошел и в тувинскую культуру, отразившись в мифологии и топонимике. Название сельского населенного пункта в Туве, в Кызыльском кожууне - Шамбалыг, происхождение которого не установлено точно, продолжает волновать и исследователей именно как возможное доказательство укоренения буддизма в Туве, важности сакральной географии в республике (Монгуш, 2012: Электр. ресурс; Монгуш, 2014: Электр. ресурс).

Буддисты России ждут того, что лидер религии снова посетит их территории, благословит их самих, их земли и религиозные центры. Такой визит трактуется как снисхождение центра буддийской геокультуры на пространство, как подтверждение того, что эта земля освящена Учением и является неотъемлемой частью буддийской геокультуры. Однако, отношение правительства Китая к Далай-ламе остается сложным долгие годы. Официальный Пекин считает его сепаратистом и всячески противится распространению его деятельности и выступлений. Конфронтация китайско-тибетского вопроса не имеет пока перспектив для разрешения (Гарри, 2016). Это сильно осложняет жизнь российских буддистов ${ }^{1}$. Итогом длительной борьбы за свои права стал лишь короткий визит Его Святейшества в Калмыкию в ноябре 2004 г. В последующие годы МИД вновь перестало выдавать Далай-ламе XIV визу на въезд в Россию (Уланов, 2010: 256).

Этот факт имеет определенное отражение в геокультурной плоскости. Несмотря на то, что сама Россия и ее власть тувинцами понимается в позитивном ключе, как пишут Е. Б. Шестопал, Н. В. Смулькина и И. В. Сорозикова, тем не менее, тувинцы определенно чувствуют отчуждение от федеральной власти и России в целом, которую они идентифицируют, прежде всего, с русскими. Авторы видят причину этой отчужденности именно в приоритете конфессиональной и этнической идентичности у тувинцев (Шестопал, Смулькина, Сорозикова, 2019: 86). То есть тувинцы, как и калмыки, и буряты, понимают свое конфессиональное отличие, меньшинство и ущемленность религиозных прав в своей стране. Это также подкрепляет чувство общности буддийских республик, много лет живущих в ожидании своего пастыря. И общность эта в первую очередь именно религиозная (Янгутов, Цыренов, 2016), поскольку в языковом отношении, например, тувинцы - тюркоязычный народ, калмыки и буряты - монголоязычный; Тува, Калмыкия и Бурятия также имеют свои особенности исторического развития (Романова, 2008). Тем не менее, для тувинцев Калмыкия и Бурятия также представляют собой буддийские геокультурные образы, территории с особым значением, где есть та же религия, где есть такие же буддисты.

Дополнительными, не столь крупными для тувинцев российскими буддийскими геокультурными образами также можно назвать образ Санкт-Петербургского храма - дацана Гунзэчойнэй, а также образы буддийских территорий Алтайского и Забайкальского краев, Читинской и Иркутской областей, где также функционируют дацаны. Разумеется, буддийские общины есть во многих городах, действуют они самостоятельно, но мы рассматриваем здесь только наиболее значительные образы для тувинцев.

Значение образы имеют разные в зависимости от точки зрения. Все указанные островки буддизма самой разной величины - в нашей стране остаются разрозненными островками. В 1991 г. была предпринята попытка провести учредительную конференцию в петербургском дацане, с тем, чтобы создать единый буддийский центр. В Москве в 1993 г. был создан Центр тибетской культуры и информации, курируемый Далай-ламой XIV, главная цель которого - возрождение буддизма в России. Тем не менее, ситуация не изменилась: каждый регион имеет свое духовное управление. Есть Буддийская традиционная сангха России и Духовное управление буддистов в Бурятии, Объединение буддистов Калмыкии и Управление Камбы-ламы в Туве (Сафронова, 2009). С одной стороны, эта разрозненность стала продолжением традиции многолетнего автономного развития буддийских общин, а с другой стороны, как пишет М. С.Уланов, буддийская идентичность в Калмыкии, Бурятии и Туве во многом

${ }^{1}$ Андросов В. П.: «К сожалению, наши политики не пускают Далай-ламу - боятся китайской ноты протеста» [Электронный ресурс] // Историческая экспертиза. URL: https://istorex.ru/Novaya_stranitsa_7 (дата обращения: 05.05.2019). 
приобрела черты культурной идентичности. Буддистом человек может считать себя потому, что он калмык, бурят или тувинец, который живет в регионе с буддийскими традициями и через эти традиции и национальную культуру ощущает свое духовное родство с буддизмом (Уланов, 2010: 242).

\section{Заключение}

Тема развития геокультурных буддийских образов тувинцев показывает один из аспектов развития собственно культуры, картины мира в культуре. Сквозь призму геокультурных образов мы можем увидеть, как тувинцы обогащали свою картину мира, расширяли понимание пространства, окружающего свою культуру, свой край, осваивая иные территории в социокультурном опыте, как входили в современный мир глобализации и регионализации, и в пространство разнообразных межкультурных контактов. Буддийская геокультура, на сегодня представляющая собой интереснейшее глобальное явление, имеет, как мы увидели как образы реальных пространств, так и «смещенных», и мифических, составляющих часть буддийской религиозной картины мира. Тувинцы, «присвоив» эти образы, сделав их своими, обогатили свое мировоззрение и идентификационную «карту».

\section{СПИСОК ЛИТЕРАТУРЫ}

Анайбан, 3. В., Тюхтенева, С. П. (2008) Этнокультурная адаптация населения Южной Сибири (современный период). М. : Институт востоковедения. 217 с.

Анайбан, 3. В. (2017) Молодежь Тувы и Хакасии в ХХІ веке. М. : ИВ РАН. 240 с.

Андросов, В. П. (2017) Шамбала // Большая российская энциклопедия : в 35 т. / гл. ред. Ю. С. Осипов. М. : Большая российская энциклопедия. Т. 34. С. 681.

Берзин, Т. (1992) Тибетский буддизм: Его история и перспективы развития. М. : Традиционная медицина. $31 \mathrm{c.}$

Буддийский взгляд на мир (1994) / сост. Е. П. Островская и В. И. Рудой. СПб.: Андреев и сыновья. 461 с.

Гарри, И. (2016) Тибетский вопрос и тибетский буддизм в Китае: реформы и конфликты // Государство, религия, церковь в России и за рубежом. № 4. С. 148-173. DOI: 10.22394/2073-7203-2016-34-4-148-173

Гачев, Г. Д. (1999) Национальные образы мира. Евразия - космос кочевника, земледельца и горца. М. : Институт ДИ-ДИК. 368 с. $352 \mathrm{c}$.

Головнев, А. В., Куканов, Д. А., Перевалова Е. В. (2018) Арктика: атлас кочевых технологий. СПб. : МАЭ РАН.

Горбатов, В. (2018) Буддисты и Советское государство в 1946-1960-е гг. // Российская история. № 5. С. 77-88. DOI: $10.31857 /$ S086956870001572-7

Донгак, В. С. (2003) Этническая этничность у тувинцев : автореф. дисс.... к. ист. н. СПб. 25 с.

Замятин, Д. Н. (2006) Культура и пространство. Моделирование географических образов. М. : Знак. 488 с.

История Тувы (2001) : в 2 т. 2-е изд. / под ред. С. И. Вайнштейна, М. Х. Маннай-оола. Новосибирск: Наука. Т. $1.367 \mathrm{c}$.

История Тувы (2007) : в 3 т. / под общ. ред. В. А. Ламина. Новосибирск : Наука. Т. 2. 430 с.

История Тувы (2016) : в 3 т. / под общ. ред. В. А. Ламина. Новосибирск : Наука. Т. 3.455 с.

Китинов, Б. У. (2018) Геокультурный образ буддизма в Каспийском регионе // Вестник Калмыцкого университета. № 38. С. 6-11.

Куулар, Д. С. (2000) Тувинский фольклор в контексте центральноазиатских устно-поэтических традиций : дисс. в форме научного доклада ... д-ра филол. наук. Улан-Удэ.

Ламажаа, Ч. К. (2013) Архаизация общества. Тувинский феномен. М. : Книжный дом «Либроком». 272 с.

Левин, Т. (2012) Музыка новых номадов. Горловое пение в Туве и за ее пределами. М. : Классика-XXI. 336 с.

Малькова, В. К., Тишков, В. А. (2009) Культура и пространство. Книга первая. Образы российских республик в Интернете. М. : ИЭА РАН. 147 с.

Маннай-оол, М. Х. (2004) Тувинцы: происхождение и формирование тувинского этноса. Новосибирск : Наука. 164 с.

Мифы, легенды, предания тувинцев (2010) / сост. Н. А. Алексеев, Д. С. Куулар, З. Б. Самдан, Ж. М. Юша. Новосибирск : Наука. 372 с.

Монгуш, А. А. (2012) «Шамбалыг» и духовная культура народов Тувы [Электронный ресурс] // Новые исследования Тувы. № 1. URL: https://nit.tuva.asia/nit/article/view/358 (дата обращения: 12.03.2019).

Монгуш, М. В. (2001) История буддизма в Туве. Новосибирск : Наука. 200 с.

Монгуш, М. В. (2010) Один народ : три судьбы. Тувинцы России, Монголии и Китая в сравнительном контексте. Осака : Национальный музей Этнологии. 360 с. 
Монгуш, М. В. (2012а) Деятельность нетрадиционных конфессий в Туве: 1990-2010 гг. [Электронный ресурс]// Новые исследования Тувы. № 1. URL: https://nit.tuva.asia/nit/article/view/353 (дата обращения: 12.03.2019).

Монгуш, М. В. (2012b) Старые и новые религии в Туве [Электронный ресурс] // Новые исследования Тувы. № 1. URL: https://nit.tuva.asia/nit/article/view/356 (дата обращения: 12.03.2019).

Монгуш, М. В. (2014) Таинственная Шамбала: реальность без вымысла [Электронный ресурс] // Новые исследования Тувы. № 2. URL: https://nit.tuva.asia/nit/article/view/170 (дата обращения: 12.03.2019).

Монгуш, М. В. (2016) Традиционный и западный буддизм в современной России: опыт сравнительного анализа [Электронный ресурс] // Новые исследования Тувы. № 1. URL: https://nit.tuva.asia/nit/article/view/69 (дата обращения: 12.03.2019).

Москаленко, Н. П. (2000) Основные проблемы этнополитической истории Тувы в ХХ в. : автореф. дисс.... к. ист. н. М. 26 с.

Потапов, Л. П. (1969) Очерки народного быта тувинцев. М. : Наука. 402 с.

Религиоведение (2007) : словарь / под ред. Е. С. Элбакян. М. : Академический проект. 637 с.

Романова, М. С. (2008) Бурятия, Калмыкия, Тува: этническая реальность глазами экспертов // Социология власти. № 6. С. 103-113.

Сафронова, Е. С. (2009) Современный буддизм в России как часть буддийской цивилизации // Государство, религия, церковь в России и за рубежом. Т. 27. № 1. С. 73-84.

«... Страданий рассеивать тьму...». Визит Далай-ламы в Туву (1995). Кызыл : Новости Тувы. 128 с.

Сузукей, В. Ю. (2009) Пространство и время в традиционной культуре тувинцев [Электронный ресурс]// Новые исследования Тувы. № 1-2. URL: https://nit.tuva.asia/nit/article/view/669 (дата обращения: 12.03.2019).

Терентьев, А. (2014) Буддизм в России - царской и советской. СПб. : Издание А. Терентьева. 484 с.

Традиционное мировоззрение тюрков Южной Сибири. Пространство и время. Вещный мир (1988) / Э. Л. Львова, И. В. Октябрьская, А. М. Сагалаев, М. С. Усманова. Новосибирск : Наука. Сибирское отделение. 225 с.

Уланов, М. С. (2010) Буддизм в социокультурном пространстве России (социально-философский анализ) : дисс.... д-ра филос. н. Ростов-на-Дону. 369 с.

Харитонова, В. И. (2018) Тувинский (нео)шаманизм как культовая и целительская практика в современном мире [Электронный ресурс] // Новые исследования Тувы. № 4. URL: https://nit.tuva.asia/nit/article/view/806 (дата обращения: 12.03.2019). DOI: 10.25178/nit.2018.4.3

Хомушку, О. М. (1998) Религия в истории культуры тувинцев. М. : б./и. 177 с.

Хомушку, О. М. (2005) Религия в культуре народов Саяно-Алтая. М. : Изд-во РАГС. 228 с.

Хомушку, О. М. (2009) Влияние буддийских космологических представлений народов Саяно-Алтая // Актуальные проблемы исследования этноэкологических и этнокультурных традиций народов Саяно-Алтая. Материалы I-й межрегиональной научно-практической конференции для молодых ученых, аспирантов и студентов / отв. ред. О. М. Хомушку. Кызыл: б. и. 124 с. С. 72-74.

Хомушку, О.М. (2010) Трансформация добуддийских архетипов в процессе их взаимодействия с буддийскими представлениями в мировоззрении народов Саяно-Алтая // Тувинская письменность и вопросы исследования письменностей и письменных памятников России и центрально-азиатского региона. Материалы международной научной конференции, посвященной 80-летию тувинской письменности : в 2 ч. / отв. ред. К. А. Бичелдей. Абакан : Хакасское книжное издательство. Ч. II. 280 с. С. 260-267.

Хомушку, О. М. Межконфессиональные отношения в Республике Тыва: проблемы и перспективы [Электронный ресурс] // Российское объединение исследователей религии. URL: https://rusoir.ru/03print/ 03print-01/03print-01-34/ (дата обращения: 12.05.2019).

Шестопал, Е. Б., Смулькина Н. В., Сорозикова, И. В. (2019) Сравнительный анализ образов своей страны у жителей российских регионов // Сравнительная политика и геополитика. Т. 10, № 3. C. 74-94. DOI: 10.24411/2221-3279-2019-10031

Янгутов, Л. Е., Цыренов, Ч. Ц. (2016) Буддизм в социокультурной традиции России // Вестник Бурятского государственного университета. Вып. 6. С. 108-119. DOI: 10.18101/1994-0866-2016-6-108-119

Дата поступления: 02.06.2019 г.

\section{REFERENCES}

Anaiban, Z. V. and Tiukhteneva, S. P. (2008) Etnokul'turnaia adaptatsiia naseleniia Iuzhnoi Sibiri (sovremennyi period) [Ethno-cultural adaptation of the population of southern Siberia: the contemporary period]. Moscow, Institut vostokovedeniia. 217 p. (In Russ.).

Anaiban, Z. V. (2017) Molodezh' Tuvy i Khakasii v XXI veke [Young people of Tuva and Khakassia Republic in the 21st century]. Moscow, IV RAN. 240 p. (In Russ.). 
Androsov, V. P. (2017) Shambala. In: Bol'shaia rossiiskaia entsiklopediia [Great Russian encyclopaedia] : in 35 vols. / ed. by Iu. S. Osipov. Moscow, Bol'shaia rossiiskaia entsiklopediia. Voi. 34. P. 681. (In Russ.).

Berzin, T. (1992) Tibetskii buddizm: Ego istoriia i perspektivy razvitiia [Tibetan Buddhism: Its history and prospects of development]. Moscow, Traditsionnaia meditsina. 31 p. (In Russ.).

Buddiiskii vzgliad na mir [The Buddhist view of the world] (1994) / comp. by E. P. Ostrovskaia and V. I. Rudoi. St. Petersburg, Andreev i synov'ia Publ. 461 p. (In Russ.).

Garri, I. (2016) Tibetskii vopros i tibetskii buddizm v Kitae: reformy i konflikty ["Tibetan question" and tibetan Buddhism in China: Reforms and conficts]. Gosudarstvo, Religiia, Tserkov'v Rossii i za Rubezhom, no. 4, pp. 148-173. DOI: 10.22394/2073-7203-2016-34-4-148-173 (In Russ.).

Gachev, G. D. (1999) Natsional'nye obrazy mira. Evraziia - kosmos kochevnika, zemledel'tsa i gortsa [National world pictures. Eurasia, space of the nomad, the farmer and the mountaineer]. Moscow, Institut DI-DIK. 368 p. (In Russ.).

Golovnev, A. V., Kukanov, D. A. and Perevalova E. V. (2018) Arktika: atlas kochevykh tekhnologii [Arctic: Atlas of nomadic technologies]. St. Petersburg, MAE RAN. 352 p. (In Russ.).

Gorbatov, V. (2018) Buddisty i Sovetskoe gosudarstvo v 1946-1960-e gg. [Buddhists and Soviet State in 19461960s]. Rossiiskaia istoriia, no. 5, pp. 77-88. DOI: 10.31857/S086956870001572-7 (In Russ.).

Dongak, V. S. (2003) Etnicheskaia etnichnost' u tuvintsev [Ethnic ethnicity of Tuvans]: Thesis of Diss.... Candidate of History. SPb. 25 p. (In Russ.).

Zamiatin, D. N. (2006) Kul'tura i prostranstvo. Modelirovanie geograficheskikh obrazov [Culture and Space. Modeling of geographical images]. Moscow, Znak. 488 p. (In Russ.).

Istoriia Tuvy [The History of Tuva] (2001) : in 2 vol. 2nd ed. / ed. by S. I. Vainshtein and M. Kh. Mannai-ool. Novosibirsk, Nauka. Vol. 1. 367 p. (In Russ.).

Istoriia Tuvy [The History of Tuva] (2007) : in 3 vol. / ed. by V. A. Lamin. Novosibirsk, Nauka. Vol. 2. 430 p. (In Russ.). Istoriia Tuvy [The History of Tuva] (2016) : in 3 vol. / ed. by V. A. Lamin. Novosibirsk, Nauka. Vol. 3. 455 p. (In Russ.). Kitinov, B. U. (2018) Geokul'turnyi obraz buddizma v Kaspiiskom regione [The geo-cultural image of Buddhism in the Caspian region]. Vestnik Kalmytskogo universiteta, no. 38, pp. 6-11. (In Russ.).

Kuular, D. S. (2000) Tuvinskii fol'klor v kontekste tsentral'noaziatskikh ustno-poeticheskikh traditsii [Tuvan folklore in the context of Central Asian oral poetic traditions] : Diss. in the form of a scientific report ... Doctor of Philology. UlanUde. (In Russ.).

Lamazhaa, Ch. K. (2013) Arkhaizatsiia obshchestva. Tuvinskii fenomen [The Archaization of society. The Tuvan phenomenon]. Moscow, Book house «Librokom». 272 p. (In Russ.).

Levin, T. (2012) Muzyka novykh nomadov. Gorlovoe penie $v$ Tuve i za ee predelami [Music of new nomads. Throat singing in Tyva and beyond]. Moscow, Klassika-XXI. 336 p. (In Russ.).

Mal'kova, V. K. and Tishkov, V. A. (2009) Kul'tura i prostranstvo. Kniga pervaia. Obrazy rossiiskikh respublikv Internete [Culture and Space. Book 1. Images of Russian republics on the Internet]. Moscow, IEA RAN. 147 p. (In Russ.).

Mannai-ool, M. Kh. (2004) Tuvintsy: proiskhozhdenie i formirovanie tuvinskogo etnosa [Tuvans: the origin and formation of the Tuvan ethnicity]. Novosibirsk, Nauka. 164 p. (In Russ.).

Mify, legendy, predaniia tuvintsev [Myths and legends of Tuvans] (2010) / comp. by N. A. Alekseev, D. S. Kuular, Z. B. Samdan and Zh. M. Yusha. Novosibirsk, Nauka. 372 p. (In Russ.).

Mongush, A. A. (2012) «Shambalyg» i dukhovnaia kul'tura narodov Tuvy ["Shambalyg" and spiritual culture of people of Tuva]. The New Research of Tuva, no. 1 [online] Available at: https://nit.tuva.asia/nit/article/view/358 (access date: 12.03.2019). (In Russ.).

Mongush, M. V. (2001) Istoriia buddizma v Tuve [The history of Buddhism in Tuva]. Novosibirsk, Nauka. 200 p. (In Russ.).

Mongush, M. V. (2010) Odin narod : tri sud'by. Tuvintsy Rossii, Mongolii i Kitaia v sravnitel'nom kontekste [One people, three fates. Tuvans of Russia, Mongolia and China in a comparative context]. Osaka, Natsional'nyi muzei Etnologii. 360 p. (In Russ.).

Mongush, M. V. (2012a) Deiatel'nost' netraditsionnykh konfessii v Tuve: 1990-2010 gg. [Activities of non-traditional religions in Tuva]. The New Research of Tuva, no. 1 [online] Available at: https://nit.tuva.asia/nit/article/view/353 (access date: 12.03.2019). (In Russ.).

Mongush, M. V. (2012b) Starye i novye religii v Tuve [Old and new religions in Tuva]. The New Research of Tuva, no. 1 [online] Available at: https://nit.tuva.asia/nit/article/view/356 (access date: 12.03.2019). (In Russ.).

Mongush, M. V. (2014) Tainstvennaia Shambala: real'nost' bez vymysla [Mysterious Shambhala: reality without fiction]. The New Research of Tuva, no. 2 [online] Available at: https://nit.tuva.asia/nit/article/view/170 (access date: 12.03.2019). (In Russ.).

Mongush, M. V. (2016) Traditsionnyi i zapadnyi buddizm v sovremennoi Rossii: opyt sravnitel'nogo analiza [Traditional and western Buddhism in Russia: a comparative study]. The New Research of Tuva, no. 1 [online] Available at: https://nit.tuva.asia/nit/article/view/69 (access date: 12.03.2019). (In Russ.). 
Moskalenko, N. P. (2000) Osnovnye problemy etnopoliticheskoi istorii Tuvy $v$ XX v. [Major problems of the ethnopolitical history of Tuva in the 20th century]: Thesis of Diss.... Candidate of History. Moscow. 26 p. (In Russ.).

Potapov, L. P. (1969) Ocherki narodnogo byta tuvintsev [Essays on everyday life of Tuvans]. Moscow, Nauka. 402 p. (In Russ.).

Religiovedenie [Religious studies]: a dictionary (2007) / ed. by E. S. Elbakian. Moscow, Akademicheskii proekt. 637 p. (In Russ.).

Romanova, M. S. (2008) Buriatiia, Kalmykiia, Tuva: etnicheskaia real'nost' glazami ekspertov [Buryatia, Kalmykia, Tuva: ethnic reality through the eyes of experts]. Sotsiologiia vlasti, no. 6, pp. 103-113. (In Russ.).

Safronova, E. S. (2009) Sovremennyi buddizm v Rossii kak chast' buddiiskoi tsivilizatsii [Present day Buddhism in Russia within the structure of Buddhist civilization]. Gosudarstvo, Religiia, Tserkov'v Rossii i za Rubezhom, vol. 27, no. 1, pp. 73-84. (In Russ.).

«... Stradanii rasseivat' t'mu...». Vizit Dalai-lamy v Tuvu ["... to dispel the darkness of suffering....". The Dalai Lama's visit to Tuva] (1995). Kyzyl, Novosti Tuvy. 128 p. (In Russ.).

Suzukei, V. Iu. (2009) Prostranstvo i vremia v traditsionnoi kul'ture tuvintsev [Space and time in traditional culture of Tuvans]. The New Research of Tuva, no. 1-2 [online] Available at: https://nit.tuva.asia/nit/article/view/669 (access date: 12.03.2019). (In Russ.).

Terent'ev, A. (2014) Buddizm v Rossii - tsarskoi i sovetskoi [Buddhism in Russia - Tsarist and Soviet]. St. Petersburg, Published by A. Terent'ev. 484 p. (In Russ.).

Traditsionnoe mirovozzrenie tiurkov Iuzhnoi Sibiri. Prostranstvo i vremia. Veshchnyi mir [Traditional worldview of Turks in South Siberia. Space and time. The material world] (1988) / E. L. L'vova, I. V. Oktiabr'skaia, A. M. Sagalaev and M. S. Usmanova. Novosibirsk, Nauka. Sibirskoe otdelenie. 225 p. (In Russ.).

Ulanov, M. S. (2010) Buddizm v sotsiokul'turnom prostranstve Rossii (sotsial'no-filosofskii analiz) [Buddhism in the socio-cultural space of Russia: a socio-philosophical analysis]: Diss.... Doctor of Philosophy. Rostov-na-Donu. 369 p. (In Russ.).

Kharitonova, V. I. (2018) Tuvinskii (neo)shamanizm kak kul'tovaia i tselitel'skaia praktika v sovremennom mire [Tuvan (neo) shamanism as a religious and healing practice in contemporary world]. The New Research of Tuva, no. 4. [online] Available at: https://nit.tuva.asia/nit/article/view/806 (access date: 12.03.2019). DOI: 10.25178/nit.2018.4.3 (In Russ.).

Khomushku, O. M. (1998) Religiia v istorii kul'tury tuvintsev [Religion in the history of Tuvan culture]. Moscow, s. n. 177 p. (In Russ.).

Khomushku, O. M. (2005) Religiia v kul'ture narodov Saiano-Altaia [Religion in the culture of the SayanoAltai peoples]. Moscow, RAGS Publ. 228 p. (In Russ.).

Khomushku, O. M. (2009) Vliianie buddiiskikh kosmologicheskikh predstavlenii narodov Saiano-Altaia [The influence of the Buddhist cosmological concepts of the peoples of Sayano-Altai]. In: Aktual'nye problemy issledovaniia etnoekologicheskikh i etnokul'turnykh traditsii narodov Saiano-Altaia [Urgent issues of the study of ethno-ecological and ethno-cultural traditions of the peoples of Sayano-Altai]. Proceedings of the 1st interregional scientific and practical conference for young scientists, postgraduates and students. Ed. by O. M. Khomushku. Kyzyl, s. n. 124 p. Pp. $72-74$. (In Russ.).

Khomushku, O. M. (2010) Transformatsiia dobuddiiskikh arkhetipov v protsesse ikh vzaimodeistviia s buddiiskimi predstavleniiami v mirovozzrenii narodov Saiano-Altaia [Transformation of pre-Buddhist archetypes in the process of their interaction with Buddhist ideas in the worldview of the peoples of Sayano-Altai]. In: Tuvinskaia pis'mennost' i voprosy issledovaniia pis'mennostei i pis'mennykh pamiatnikov Rossii i tsentral'no-aziatskogo regiona [Tuvan writing and research of writings and written monuments of Russia and the Central Asian region]. Proceedings of the international scientific conference on the 80th anniversary of the Tuvan writing: in 2 vol./ ed. by K. A. Bicheldei. Abakan, Khakasskoe knizhnoe izdatel'stvo. Vol. II. 280 p. Pp. 260-267. (In Russ.).

Khomushku, O. M. Mezhkonfessional'nye otnosheniia v Respublike Tyva: problemy i perspektivy [Interfaith relations in the Republic of Tuva: problems and prospects]. Rossiiskoe ob'edinenie issledovatelei religii [online] Available at: https://rusoir.ru/03print/03print-01/03print-01-34/ (access date: 12.05.2019). (In Russ.).

Shestopal, E. B., Smul'kina N.V. and Sorozikova, I. V. (2019) Sravnitel'nyi analiz obrazov svoei strany u zhitelei rossiiskikh regionov [Comparative analysis of one's own country images in Russian regions]. Sravnitel'naia politika i geopolitika, vol. 10, no. 3, pp. 74-94. DOI: 10.24411/2221-3279-2019-10031 (In Russ.).

Iangutov, L. E., Tsyrenov, Ch. Ts. (2016) Buddizm v sotsiokul'turnoi traditsii Rossii [Buddhism in Russian Social and Cultural Tradition]. Vestnik Buriatskogo gosudarstvennogo universiteta, vol. 6, pp. 108-119. DOI: 10.18101/1994-0866-2016-6-108-119 (In Russ.). 